\title{
Build back better: Avoid the learning loss trap
}

\author{
Yong Zhao ${ }^{1,2}$
}

Accepted: 15 January 2021 / Published online: 4 March 2021

(C) UNESCO IBE 2021

\begin{abstract}
A dangerous trap exists for educators and education policy makers: the learning loss. This trap comes with a large amount of data and with sophisticated projection methods. It presents a stunningly grim picture for education and it invites educators and policy makers to make wrong decisions and invest in wrong things. The article identifies a number of undesirable outcomes that their concerns could lead to. It also suggests several productive actions when the pandemic is controlled and schools reopen.
\end{abstract}

Keywords Learning loss $\cdot$ Learning outcomes $\cdot$ Covid-19

A dangerous trap exists for educators and education policy makers. This trap comes with a large amount of data and with sophisticated projection methods. It presents a stunningly grim picture for education. This trap invites educators and policy makers to make wrong decisions and invest in wrong things.

\section{The learning loss}

The trap is the so-called learning losses during the Covid-19 pandemic. A number of organizations and individuals have put out various estimates about what students have lost due to school closures and remote learning during the pandemic. For example, the global consulting firm McKinsey produced two reports about these learning losses. As late as December 8, 2020, McKinsey said, "Students, on average, started school about three months behind where we would expect them to be in mathematics" and "Students of color were about

Yong Zhao

yongzhaoeducation@gmail.com

1 Melbourne Graduate School of Education, University of Melbourne, Kwong Lee Dow Building, 234 Queensberry Street, Parkville, VIC 3053, Australia

2 School of Education, University of Kansas, Lawrence, USA 
three to five months behind in learning; white students were about one to three months behind" (Dorn et al. 2020). The Center for Research on Educational Outcomes (CREDO 2020) at Stanford University issued a press release stating that "the average estimates of how much students lost in the Spring of 2020 ranged from 57 to 183 days of learning in Reading and from 136 to 232 days of learning in Math" (para. 2). Other organizations, such as the assessment company NWEA (Kuhfeld and Tarasawa 2020) and the Annenberg Institute at Brown University (Santibanez and Guarino 2020), have also published reports about learning losses. The Organization for Economic Cooperation and Development (OECD) published a projection for the economic losses due to learning losses as \$14 trillion over the next 80 years (Hanushek and Woessmann 2020).

These estimates have caught the attention of policy makers and educators. Governments, school leaders, and teachers are all concerned about the learning loss students may experience due to the Covid-19 pandemic. After all, schools have been seriously disrupted, as have students and their families. The pandemic has, in more ways than one, significantly affected learning and school operations. It seems only natural to want to know the extent of the learning loss students have experienced and then take actions to hopefully make up for the losses.

\section{Possible mistakes}

This is wherein the trap lies. There is nothing wrong with making estimates about learning losses, but the possible actions these projections can induce are worrisome because they can, at best, waste resources and, at worst, lead post-pandemic education in the wrong direction. The concerns of educators and policy makers are to be expected, but these policy makers could end up investing in unproductive educational efforts. Below are a number of undesirable outcomes that their concerns could lead to.

Governments may decide to launch standardized assessments to track students' learning losses. It is possible that educational policy makers may be so interested in learning the extent of loss experienced by students that they will use standardized testing to assess all students. The desire to know the overall extent of loss and what achievement gaps may exist between different groups of students is completely understandable, but standardized testing can be the worst way to collect such data for two major reasons.

First, any standardized testing given to all students will have a typically limited scope, with a focus on math and reading. In other words, what will be measured is not the entirety of students' learning but a small piece of their overall education. Even assuming that the assessments are highly accurate (which they are not), they would miss other equally and perhaps more important aspects of learning, such as confidence, self-determination, creativity, entrepreneurial thinking, and other subjects.

Education has many desirable outcomes (Zhao 2017, 2018b). These outcomes can be short term or long term, cognitive and non-cognitive, and instructional and educational. Short-term, cognitive, and instructional outcomes do not necessarily translate directly into long-term, non-cognitive, and educational outcomes. For example, test scores have often been found to have a negative correlation with students' confidence and well-being (Loveless 2006; OECD 2019; Zhao 2018b). Test scores have also been found to have a negative correlation with economic development and entrepreneurial confidence and activities across (Baker 2007; Tienken 2008; Zhao 2012). Test scores do not predict the future of an individual's success very well, and non-cognitive skills may play a bigger role than 
cognitive skills play (Brunello and Schlotter 2010; Levin 2012). Some assessments show successes that are only productive in the short term, while failures may actually be more productive in the long term (Dean and Kuhn 2007; Kapur 2014, 2016).

We are used to assessing math and reading and to ignoring other school subjects and non-cognitive and long-term educational outcomes. When the results are released, all attention will be on what was assessed. We can predict that if governments conduct standardized assessments of learning losses in math and reading, attention will be paid to math and reading, and efforts may be directed toward improving these two subjects. This would be disastrous because all other important educational outcomes would be ignored.

Second, standardized testing will inevitably put pressure on students, take time away from learning, and cost a lot of money. It may not be wise to place students, who have just experienced a terrible pandemic, in a situation of unnecessary pressure. Students at this time need a warm, friendly, welcoming educational experience instead of one that checks on them. It is also important to spend time working with students and to support their learning instead of taking time away from that for testing. Of course, given the economic downturn, money should be spent on students' learning instead of on testing students.

Governments may also decide to direct more money and efforts to math and reading to help students recover from the losses. Some may want to implement remediation or force schools to spend more time in these two areas. This would be a great mistake for a number of reasons.

First, the loss is not only in reading and math. Although reports of learning loss typically focus on these two areas, students have experienced losses in all aspects of learning. The pandemic affected not only learning in reading and math but also the learning of each student as a whole person. The loss includes areas that are much more important than reading and math, such as social emotional well-being, attitudes toward learning, interactions with friends, and physical and psychological development.

Second, the loss is different for different students. A focus on reading and math may not be needed for students who have not experienced a learning loss in those subjects. Such a focus may deprive these students of learning opportunities in other areas (Tienken and Zhao 2013).

Third, the idea that the loss can be remediated without sacrificing in other areas is not realistic. It is possible that whatever learning was lost during the pandemic can be gradually remediated in the long run, but students cannot make up for those losses in the short term. It is thus dangerous to have students focus on math and reading when schools reopen to normalcy, because such a focus would come at the cost of other subjects and educational outcomes. Time is a constant, and spending more time on reading and math would certainly take time away from other school subjects (Zhao 2018b). It is also possible that a direct-instruction style of remediation could damage students' curiosity and active engagement with learning (Bonawitza et al. 2011; Buchsbauma et al. 2011).

\section{Build back better}

We can undertake a number of productive actions when the pandemic is controlled and schools reopen, instead of being trapped by the so-called learning losses in math and reading.

Meet the students where they are. Students will return to school with different experiences of the pandemic. Instead of treating them as one homogenous group, we should treat 
them as individuals. It is counterproductive to assume a uniform learning loss across all students as group. Rather, we should encourage teachers to use their professional judgment to work with each and every student, to teach whatever is necessary rather than what is expected by the government, and to build relationships with all students.

Pay attention to all educational outcomes. Human society is in a time of uncertainty, and the future is unknown. Historically speaking, it may be accidental that the pandemic took place in 2020, but the massive technological changes are real (Schwab 2015). We cannot predict exactly what knowledge and skills will be needed in the future. We also know that students have different talents, experiences, and passions. Thus, we must work on all educational outcomes and developing all students for a different society post Covid-19.

Engage learners as partners of change and owners of their learning. Students are not passive recipients but active creators of learning (Zhao 2011, 2018a). Covid-19 may have affected many students negatively, but their experience may also have helped them develop more independence, more resilience, and a broader sense of society and learning. This would be a great time to help students personalize their learning experiences and become self-determined learners (Wehmeyer and Zhao 2020).

Keep families engaged. Families play a significant role in students' education, and the pandemic has led to an increase in family involvement in education (Garbe et al. 2020; Gutierrez et al. 2020). Schools have developed more ways to connect with parents, and parents have spent more time on their children's education. This positive development should be kept and expanded after the pandemic has been controlled.

Keep online/remote learning. Almost all schools have developed forms of online or remote learning opportunities for students during the pandemic. While not all programs have been as successful as face-to-face teaching, this has been a major innovation for schools. Online/remote learning can expand our thinking about education and expand learning beyond the physical classroom. This innovation should be kept so that teachers and students can bring global resources to the classroom and participate in global learning programs.

Build back better. Build Back Better (BBB) is a strategy endorsed by the United Nations that aims at reducing the risk of future disasters and shocks. After the Covid-19 pandemic, we need to build back our schools better, not only to reduce future risks but also to address our previous dissatisfactions. The pandemic, with its huge impact on education, is a rare opportunity for us to rebuild our education.

\section{References}

Baker, K. (2007). Are International tests worth anything? Phi Delta Kappan, 89(2), 101-104.

Bonawitza, E., Shaftob, P., Gweonc, H., Goodmand, N. D., Spelkee, E., \& Schulzc, L. (2011). The double-edged sword of pedagogy: Instruction limits spontaneous exploration and discovery. Cognition, 120(3), 322-330.

Brunello, G., \& Schlotter, M. (2010). The effect of non cognitive skills and personality traits on labour market outcomes. Analytical report for the European Commission prepared by the European Expert Network on Economics of Education (EENEE). https://ideas.repec.org/p/iza/izadps/dp5743.html.

Buchsbauma, D., Gopnika, A., Griffithsa, T. L., \& Shaftob, P. (2011). Children's imitation of causal action sequences is influenced by statistical and pedagogical evidence. Cognition, 120(3), 331-340.

CREDO [Center for Research on Education Outcomes] (2020). CREDO at Stanford University presents estimates of learning loss in the 2019-2020 school year. Palo Alto, CA: Stanford University. https:// credo.stanford.edu/sites/g/files/sbiybj6481/f/press_release_learning_loss.pdf.

Dean, D., \& Kuhn, D. (2007). Direct instruction vs. discovery: The long view. Science Education, 91(3), 384-397. 
Dorn, E., Hancock, B., Sarakatsannis, J., \& Viruleg, E. (2020, December 8). Covid-19 and learning loss: Disparities grow and students need help. New York, NY: McKinsey. https://www.mckinsey.com/indus tries/public-and-social-sector/our-insights/covid-19-and-learning-loss-disparities-grow-and-stude nts-need-help.

Garbe, A., Ogurlu, U., Logan, N., \& Cook, P. (2020). Parents' experiences with remote education during Covid-19 school closures. American Journal of Qualitative Research, 4(3), 45-65.

Gutierrez, L. A., Hernandez, L., Kim, T., Kuttner, P. J., Lopez, G. R., Mayer-Glenn, J., Niang, A., \& Yanagui, A. (2020). Family-school relationships are the missing link in Covid-19 era education. Education Week. https://www.edweek.org/leadership/opinion-family-school-relationships-are-the-missing-linkin-covid-19-era-education/2020/10.

Hanushek, E. A., \& Woessmann, L. (2020). The economic impacts of learning losses. Paris: OECD. https:// www.oecd.org/education/The-economic-impacts-of-coronavirus-covid-19-learning-losses.pdf.

Kapur, M. (2014). Productive failure in learning math. Cognitive Science, 38(5), 1008-1022.

Kapur, M. (2016). Examining productive failure, productive success, unproductive failure, and unproductive success in learning. Educational Psychologist, 51(2), 289-299.

Kuhfeld, M., \& Tarasawa, B. (2020). The Covid-19 slide: What summer learning loss can tell us about the potential impact of school closures on student academic achievement. Portland, OR: NWEA. https:// www.nwea.org/content/uploads/2020/05/Collaborative-Brief_Covid19-Slide-APR20.pdf.

Levin, H. M. (2012). More than just test scores. Prospects, 42(3), 269-284.

Loveless, T. (2006). How well are American students learning? Washington, DC: Brookings Institution. https://www.brookings.edu/wp-content/uploads/2016/06/10education_loveless-1.pdf.

OECD (2019). PISA 2018 results (Volume III): What school life means for students' lives. Paris: OECD. https://doi.org/10.1787/acd78851-en.

Santibanez, L., \& Guarino, C. (2020). The effects of absenteeism on cognitive and social-emotional outcomes: Lessons for Covid-19. Providence, RI: Annenberg Institute, Brown University. https://doi.org/ $10.26300 / \mathrm{yj} 9 \mathrm{~m}-\mathrm{x} 430$.

Schwab, K. (2015, December 12). The fourth industrial revolution: What it means and how to respond. Foreign Affairs. https://www.foreignaffairs.com/articles/2015-12-12/fourth-industrial-revolution.

Tienken, C. H. (2008). Rankings of international achievement test performance and economic strength: Correlation or conjecture? International Journal of Education Policy and Leadership, 3(4), 1-15.

Tienken, C. H., \& Zhao, Y. (2013). How common standards and standardized testing widen the opportunity gap. In P. L. Carter \& K. G. Welner (Eds.), Closing the opportunity gap: What America must do to give every child an even chance (pp. 113-122). Oxford: Oxford University Press.

Wehmeyer, M., \& Zhao, Y. (2020). Teaching students to become self-determined learners. Alexandria, VA: Association for Supervision and Curriculum Development (ASCD).

Zhao, Y. (2011). Students as change partners: A proposal for educational change in the age of globalization. Journal of Educational Change, 12(2), 267-279. https://doi.org/10.1007/s10833-011-9159-9

Zhao, Y. (2012). World class learners: Educating creative and entrepreneurial students. Thousand Oaks, CA: Corwin.

Zhao, Y. (2017). What works can hurt: Side effects in education. Journal of Educational Change, 18(1), 1-19.

Zhao, Y. (2018a). Reach for greatness: Personalizable education for all children. Thousand Oaks, CA: Corwin.

Zhao, Y. (2018b). What works may hurt: Side effects in education. New York, NY: Teachers College Press.

Publisher's Note Springer Nature remains neutral with regard to jurisdictional claims in published maps and institutional affiliations.

Yong Zhao is Foundation Distinguished Professor in the School of Education, University of Kansas, and Professor at the Melbourne Graduate School of Education. He previously served as the Presidential Chair, Associate Dean, and Director of the Institute for Global and Online Education in the College of Education, University of Oregon, where he was also a professor in the Department of Educational Measurement, Policy, and Leadership. Dr. Zhao has published more than 100 articles and 30 books. He has received numerous awards, including the Early Career Award from the American Educational Research Association, Outstanding Public Educator from Horace Mann League of USA, and Distinguished Achievement Award in Professional Development from the Association of Education Publishers. He is an Elected Fellow of the International Academy for Education and is recognized as one of the most influential education scholars. 